\title{
Analyzing Enterprise Networks Needs: Action Research from the Mechatronics Sector
}

\author{
Luca Cagnazzo $^{1}$, Paolo Taticchi ${ }^{1}$, Gianni Bidini ${ }^{1}$, and Enzo Baglieri ${ }^{2}$ \\ ${ }^{1}$ Department of Industrial Engineering, University of Perugia, Via Duranti 67, Perugia, Italy \\ luca.cagnazzo@unipg.it, paolo.taticchi@unipg.it, \\ gbid@mach.ing.unipg.it \\ ${ }^{2}$ SDA Bocconi School of Management, Via Ferdinando Bocconi, 8, Milan, Italy \\ enzo.baglieriasdabocconi.it
}

\begin{abstract}
New business models and theories are developing nowadays towards collaborative environments direction, and many new tools in sustaining companies involved in these organizations are emerging. Among them, a plethora of methodologies to analyze their needs are already developed for single companies. Few academic works are available about Enterprise Networks (ENs) need analysis. This paper presents the learning from an action research (AR) in the mechatronics sector: AR has been used in order to experience the issue of evaluating network needs and therefore define, develop, and test a complete framework for network evaluation. Reflection on the story in the light of the experience and the theory is presented, as well as extrapolation to a broader context and articulation of usable knowledge.
\end{abstract}

Keywords: Enterprise Network, SME, Network analysis.

\section{Introduction}

Today acceleration and complexity of technological changes, globalization of markets and demanding customers, make companies look for new ways to stay ahead of the competition. Particularly, in the case of Small \& Medium Enterprises (SMEs), additional difficulties arise due to their small size, which must be borne in mind [1]. In this knowledge-based economy, the key factor for obtaining a competitive edge for SMEs lies in their capacity to acquire and absorb knowledge, to develop new products and processes, and to study the best business practices [2]. In order to do this, among other factors, it is important for SMEs to strengthen ties with other companies and organizations by creating inter-organizational networks. Cooperation with other companies of similar or bigger size is an alternative strategy that allows them to make use of the competitive edge of the associated companies, whether they are vertical or horizontal networks. In these new forms of collaboration among small companies, new forms of competence measurement and adequate methodologies for analyze the partner needs should be developed, in order to increase their competitiveness. For these reasons Action Research (AR) has been used in order to experience the issue of evaluating network needs and therefore define, develop, and test a complete framework for networks' evaluation. This paper is organized as follows. In the next section, 
the research methodology adopted is presented. Consequently, the SME context is presented in respect of networking issues. Further, the methodology extrapolated from the AR is presented, by highlighting its applicability to a broader context. Then, the AR context and the activities are presented. Conclusion section ends.

\section{Research Methodology}

This kind of research can be characterized as being exploratory in nature and longitudinal; the project took 1 year to be completed. During this extended period of study the authors supported the network involved in the project from its inception, participating with the network enterprise owners and managers in the problem solving of evaluating network needs. Formal project management methods and a variety of data collection techniques were also utilized during this process, e.g. direct observation, surveys, interviews and customer oriented focus groups, as well as direct participation in meetings, marketing activities and product development projects. From this point of view our work might be further classified as AR as defined by [3] since in this approach "The action researcher is not an independent observer, but becomes a participant, and the process of change becomes the subject of research". [4] emphasizes the importance of this approach in building theory in complex situations, arguing that "the grounded, iterative, interventionist nature of AR ensures closeness to the full range of variables in setting where those variables may not all emerge at once" and that "AR requires us to be creative, because, it is usually conducted to develop a new approach or solution to a situation for which there is no existing prescription". [5] highlights eight major characteristics of AR:

1-Action researcher not limit to observe but take action; 2-AR involves two goals: problem solving and contribute to science; 3 -AR require cooperation between the researchers and the client personnel; 4-AR aims at developing holistic understanding and recognition of complexity; 5-AR is fundamentally about the comprehension and investigation of change; 6-Ethical issues have to be understood since the close cooperation between the researchers and the client personnel; 7-AR includes all types of data gathering methods; 8-The action researcher should have a pre-understanding of the company business and environment.

\section{Context: SMEs and Networking}

SMEs have to make changes in the form of their organizations and of doing business in order to evolve and adapt themselves to a knowledge-based economy. These changes have to include the creation of inter-organizational cooperation. The most usual type of cooperation is an association between its own suppliers and clients or cooperation with other companies in the same sector or geographical region. Network analysis is an approach to the analysis of cooperation among companies, which has increased greatly in recent years, especially in the form of Virtual Organizations (VOs). The analysis of this type of organization gives three principal sources of value social structure, learning and generation of external economies in the network [6]. Research in cooperated systems has contributed to characterizing the following benefits for SMEs correlated to the relationship of cooperation among companies [7], [8], 
[9], [10] and [11]: increment of the market share; improvement of efficiency in using the company's asset; improvement of the level of services offered to clients; time reduction in developing a new product; sharing and cost reduction correlated to the development of new product; reduction of the risk in relation to the failure in the development of a new product; improvement of the quality of product; improvement of the level of competence and acquaintances inside the company; possibility to take advantage in a more effective way of company economies; reduction of stocks; facilitating access to the market. Further motives for engaging in inter-organizational ties and co-operation include access to information, resources, markets and technologies [12]. On the other hand, networking of enterprises entails new organizational problems, such as the decentralization of decision-making process and the horizontal coordination between different business functions as well as, outside the firm, between complementary activity performed by suppliers and customers [13] and [14]. Different researchers have attempted to assess the impact of networking in enterprises performance [15] and [16]. Understanding the performances in terms of competences and attitudes of the partner network is a fundamental task for the environmental competitiveness. Although it is an important issue for these new forms of collaboration, few studies are available in literature.

\section{Analyzing Enterprise Networks Needs}

In this section, the methodology extrapolated from the AR is presented by highlighting its applicability to a broader context. The methodology proposed relies on two elements (an auto-evaluation questionnaire, an evaluation matrix) that are further explained.

\subsection{The Questionnaire Structure}

The methodology proposed consists in an auto-evaluation process based on a questionnaire which can be submitted to the network companies. Through the questionnaire, the analysts (in the AR the authors) can achieve the classification of firms in classes of affiliation through the parameterization of several critical aspects for the network competitiveness. Particularly, data collected from the questionnaire allow the analysts to classify and group the network companies in a 4x4 evaluation matrix, after a parameterization of the manipulated information. The matrix realized by the authors cross the "technical-productive managerial competences" with the "industrial technologies appropriateness" of the companies. The first dimension highlights the managerial competences in the company operations and underlines the gaps with the best practices. The second dimension points out the status of the technology use adopted by the companies. Thus, the matrix does not allow the analysts to know the entire system as a whole, but it represents a useful tool for having a picture of the companies' situation and to deeply analyse the managerial and technological conditions of the network companies. The questionnaire and the related auto evaluation model structure consist of two main sections (Figure 1-a). 


\subsection{The Dimensions of the Auto-evaluation Questionnaire}

As introduced before, the Managerial Competences dimension and the Technological Appropriateness dimension, $\mathrm{X}$ and $\mathrm{Y}$ branches respectively in the tree in Figure 1-a, are investigated through an auto-evaluation questionnaire. Regarding the managerial competences and in particular the product/process coherence (X.1 branch of the tree), the authors evaluated the answers furnished by the companies of the network, following a methodology that confronts the product structures, in terms of mix and volumes, with the process structures (adapted from [17]), as shown in Figure 1-b. The products can be indeed realized in different ways, from a unique prototype (specialty) to standardized products (commodity) with obvious volume increasing. The productive processes can be instead defined from fragmentary to an high degree of continuity. The intersectional squares in the matrix can highlight physiological "status" of the analyzed companies or pathological "states" of inefficiency. In particular, the right upper part of the matrix represents cost-opportunity areas, since standardized products are realized with high flexible processes. Vice versa, the left lower area represents a situation in which non-standard productions are realized through high automated and standardized processes; this situation points out a clear inefficiency, since company doesn't benefit from the massive production. The positioning along the diagonal line corresponds to an high coherence between the product and the productive processes. Upper and lower positions identify non-coherence areas, corresponding to a 1-4 value score for the company and definable with the following scale: a 4 score for optimal values (along the diagonal), good values (3-squares), inappropriate values (2-sqaures) and a 1 score for critical values (1-squares). Regarding the second aspect of the Managerial Competences area, that is the operation management dimensions (X.2 branch of the tree), the analysis is conducted by the authors evaluating the second part of the questionnaire with a 1-4 answer score scale. For each operation area (quality, production, logistic, ICT), the answer scores have been parameterized on a new 1-4 value scale, that allows the authors to give an overall evaluation for each company on these areas. In this way the managerial competences have been measured for each of the investigated aspects. In order to assign an evaluating score to the "Technicalproductive managerial competence" global section (X. branch of the tree in Figure 1a), another parameterization on a 1-4 value score has been performed by the authors as average (taking in consideration particular weight values) between "ProductProcess combination coherence" (X.1 branch) and "Operation management" (X.2 branch). The score attributed to the global "Technical-productive management competence" represents the value of the x-axis of the final matrix, presented in the next paragraph for the classification of the companies. Regarding the Technological appropriateness dimensions, and in particular the three industrial technological classes, the investigation has been conducted by the authors following a similar criterion of the previous dimension. For each of the analyzed aspects, the authors realized a 1-4 score evaluation on the specific technology role for the company competitiveness in the belonging business sector, the impact of the adopted technology on the customer perception and the technology innovation degree. 


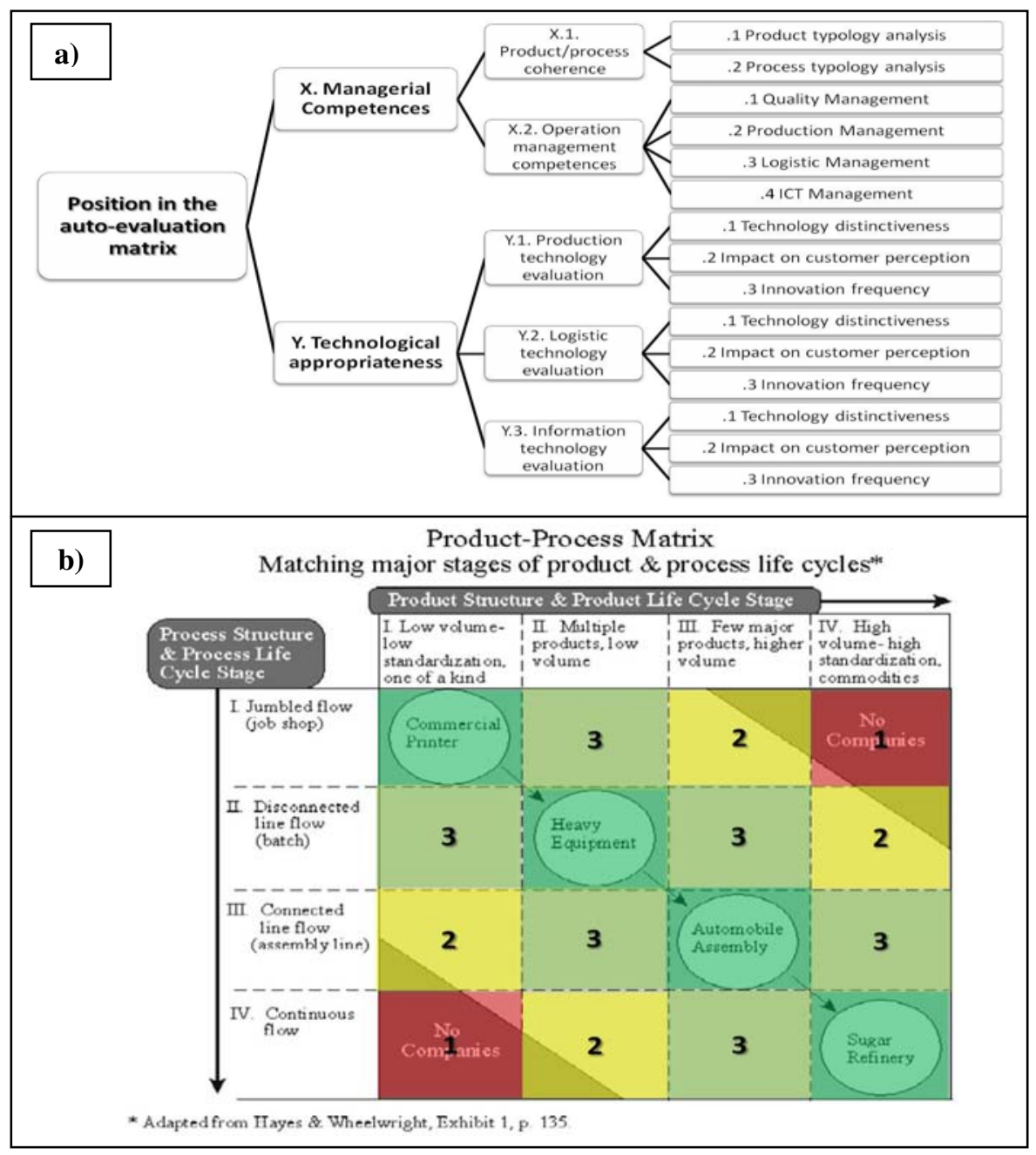

Fig. 1. a) The questionnaire structure and b) the Product-Process Matrix

\subsection{The Evaluation Matrix}

The model used for the auto-evaluation matrix is based on the balancing principal between management competences and technological potentialities. The aim of the two main sections is to classify the global technological appropriateness and managerial competences, with the 1-4 weight scale developed on the results of the questionnaire. The crossing between these two values can be summarized in a $4 \times 4$ matrix as reported in Figure 2. The orange zones in the matrix are the problematic areas in which the weaknesses in one of the two dimensions are symptoms of a low company competitiveness. The yellow zones are areas in which companies present good potentialities but they cannot use all of them since a mismatching between managerial 
competences and industrial technology appropriateness. The green zones identify non-critical situations for the companies, but they don't still represent a full excellence. The last quadrant on the bottom-right represents the best positioning in the market and the excellence benchmarking for all the other companies.

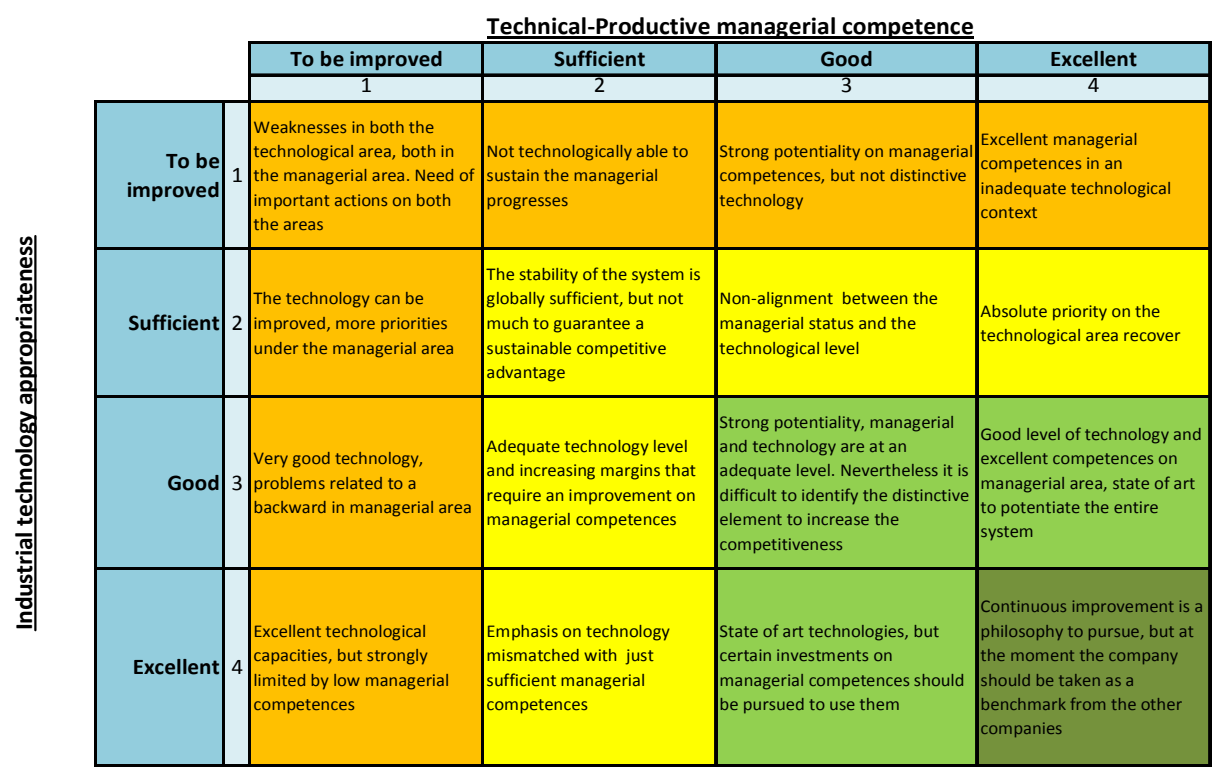

Fig. 2. Classification and evaluation matrix

\section{The Action Research Context}

The project has been conducted in an Italian network of 39 manufacturing SMEs, belonging to the mechatronics sector. This is a valuable sample of companies because it represents the main part of industries belonging to this particular sector in the Umbria region, in the central part of Italy. The network global turnover is $752 \mathrm{M€}$ and it has 4.490 total employees working within the 39 companies. The average dimension of the companies is $18 \mathrm{M} €$ turnover and 115 employees. In the $35 \%$ of the cases, the companies work on customer commitments; the remaining part of the sample has a more standardized product portfolio and in the $29 \%$ the normal ordering process is based on standard products catalogues. The companies of the network increased the selling growing rate of $11 \%$ in the last three years versus an average profitability before taxes of $5,8 \%$. Under an economic-financial point of view, all the companies performances are in the average sector indicators. Referring to the internationalization process, its impact is the $33,8 \%$ of the total turnover. Research \& Development (R\&D) investments are contained: it is the $2,1 \%$ of total turnover with a number of 9,43 employees specifically dedicated to the R\&D. These values are however higher than the national average. All the companies are deeply different for products, organizational adopted structure, technologies and governance. This apparent heterogeneity however allows the network to find new business solutions, developing new products 
and services, as well as to increase their competitiveness since the collaboration among them.

\section{Action Research: Data Gathering and Analysis}

\subsection{Data Gathering}

The project has been conducted in 2008. Data gathering has been performed through: a simple software tool to help the matrix fulfilment in the companies; and an electronic guide that helps companies in the correct use of the matrix.

Through the implementation of the matrix in the 39 companies of the case study network, final documents for each of them have been prepared, in which the own results of the analysis are presented, the needs of the firm are highlighted and preliminary solutions are discussed. A final document with aggregated data and cluster analysis, in which a picture of the network state is showed and further resolving problem actions discussed has been realized.

\subsection{Data Analysis}

Trough the research methodology explained in the previous paragraphs, authors present in this section the results of the analysis conducted within the network. In particular the classification of the partners through the evaluation matrix is caught out and the data analysis follows. The investigated companies show a strong industrial and technological identity, that allow them to cover the explicit weaknesses showed in the managerial profile. As shown in Figure 3, 23 of the 39 companies are characterized by a good technological profile (value 3), while just 14 show a good managerial competence level in the technical-productive area.

\begin{tabular}{|c|c|c|c|c|c|}
\hline & \multicolumn{4}{|c|}{ Technical-Productive managerial competence } \\
\hline & & To be improved & Sufficient & Good & Excellent \\
\hline & & 1 & 2 & 3 & 4 \\
\hline \multirow{4}{*}{ 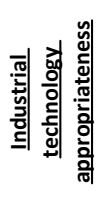 } & $\begin{array}{r}\text { To be } \\
\text { improved }\end{array}$ & 1 company & 2 companies & 1 company & - \\
\hline & Sufficient 2 & 3 companies & 6 companies & 3 companies & - \\
\hline & Good 3 & 3 companies & 10 companies & 10 companies & - \\
\hline & Excellent 4 & - & - & - & - \\
\hline
\end{tabular}

Fig. 3. Evaluation matrix for the case study network

Moreover, 7 of the 39 companies are characterized by a critical situation related to the managerial profile and they need aids since their short term visions and competitive weaknesses. 10 of the 39 companies are collocated in the good performance quadrant and they attain both the matrix dimensions with a good degree of satisfaction. Under the managerial point of view, 32 of the 39 companies of the network highlight a productive system non-aligned with the product characteristics. This finding is pointed out through the data analysis from the product-process coherence matrix (Figure 1-b). In these cases the company timeliness in response to the rapid changing 
of the market demand has been mismatched with a quick productive system review. This phenomenon is comprehensible in a short term period, but very few companies are nowadays investing in order to heal the weaknesses of their operation management system in the next 3 year period. The most critic area is the logistic one, with 24 companies showing difficulties on this topic. This is due to a misunderstanding of the logistic role in the supply chain management; companies treat logistic just as strictly related to transport and shipping. Contrarily, the quality management is very well developed within the companies of the network, confirming the historical attention of Italian industry for this topic. Moreover, they very pay attention to the production management in general, as well as to the Human Resource Management (HRM) and to the organization intellectual capital. These peculiarities should be strengthened and kept hold for next years. Under the technological profile, the company analysis has highlighted some excellent situations regarding the core technologies, for maintaining and increasing the own competitiveness. However, in some occasions this attention at the technology role becomes an exasperated behavior that lead companies to frequently renew them, under a five year period. 16 companies highlight strong weaknesses under the logistic area in terms of technology, low hardware and software automation warehouse level. The recognizing, tracing, traceability, controlling and movement systems are often manual and obsolete. This is negative for the involved companies, since on the one hand this implies an heavy weak capacity to serve customers, on the other hand it decrease the economical performances of the companies, with excessive stock quantities and very low material rotation rates. 15 companies show to heavy undervalue the Information \& Communication Technology (ICT) contributes for their own businesses. Hardware obsolete tools, inadequate infrastructures, non-appropriated low-price managerial software seem to be particularly critic topics as obstacles for the potential development of the single companies and of the network as a whole.

\section{Conclusions}

This paper, based on an AR, offered a structured methodology, based on autoanalysis, for evaluating the technological and managerial competences of enterprise networks. Through the use of a questionnaire, the methodology proposed offers the possibility to classify firms in class of affiliation through the parameterization of several investigated key performance indicators. The use of visualization matrixes permits to easily identify those network companies which lack particular technological or managerial competences, and therefore significant information is collected for the development of cluster improvement initiatives. The objective of the network investigation performed by the authors is the development, testing and strengthening of an auto-analysis model that can allow the users to investigate the technological and management competences of the collaborative environment and therefore identify the needs for a global competitiveness increasing. The usefulness of the auto evaluation tool is tangible under three different point of views: 1-For the enterprise that performs the auto evaluation activity, through which it increases the knowledge of its strengths and weaknesses, with the aim to start the appropriate improving actions; 2-For the entire network since it allows to continuously develop a benchmarking activity 
through a systematic approach, guaranteed by the rigour of the used methodology; 3For all the stakeholders involved within and outside the network, because it permits to focalize the actions on sustaining innovation and improving the local industrial system performance, thank to the guide lines developed from the observed network data interpretation.

Future research will focus on building theory from this AR so as to validate the model proposed and enlarge the context of applicability.

\section{References}

1. Gilmore, A., Carson, D., Grant, K.: SME marketing in practice. Marketing Intelligence and Planning 19(1), 31-38 (2001)

2. Collison, C., Parcell, G.: Learning to Fly: Practical Lessons from One of the World's Leading Knowledge Companies, Capstone (2001)

3. Benbasat, I., Goldestein, D.K., Mead, M.: The case research strategy in studies of information systems. MIS Quarterly, 369-386 (September 1987)

4. Westbrook, R.: Action research: a new paradigm for research in production and operations management. International Journal of Operations and Production Management 15(12), 620 (1994)

5. Gummesson, E.: Qualitative methods in management research, 2nd edn. Sage, Thousand Oaks (2000)

6. Lazzarini, S.G., Chaddad, F.R., Cook, M.L.: Integrating Supply Chain and Network Analyses: The Study of Netchains. Journal on Chain and Network Science 1(1), 7-22 (2001)

7. Lewis, D.J.: Partnership for profit: structuring and managing strategic alliances. The Free Press, New York (1990)

8. Parker, H.: Inter-firm collaboration and new product development process. Industrial Management \& Data Systems 100(6), 255-260 (2000)

9. McLaren, T., Head, M., Yuan, Y.: Supply Chain collaboration alternatives: understanding the expected costs and benefits. Internet Research: Electronic Networking Applications and Policy 2(4), 348-364 (2000)

10. Horvath, L.: Collaboration: the key to value creation in supply chain management. Supply Chain Management: An International Journal 6(5), 205-207 (2001)

11. Holton, J.A.: Building trust and collaboration in virtual team. Team Performance Management: An International Journal 7(3-4), 36-47 (2001)

12. Gulati, R., Nohria, N., Zaheer, A.: Strategic networks. Strategic Management Journal 21, 203-215 (2000)

13. Ghoshal, S., Bartlett, C.: The multinational corporation as an interorganizational network. Academy of Management Review 15, 603-625 (1990)

14. Ernst, D.: From partial to systemic globalization: international production networks in electronics industry. Berkley Roundtable on the International Economy (BRIE), Working Paper 98 (1997)

15. Easton, G., Quayle, M.: Single and Multiple Network Sourcing - Network Implications. In: Proceeding of 6th IMP Conference, Milan, pp. 474-488 (1990)

16. Puto, C., Patton, W., King, R.: Risk Handling Strategy in Industrial Vendor Selection Decisions. Journal of Marketing 49, 89-98 (Winter 1985)

17. Hayes, R.H., Wheelwright, S.C.: Link manufacturing process and product life cycles. Harvard Business Review, 133-140 (January-February 1979) 